\title{
Simple One-Pot Synthesis of Hexagonal ZnO Nanoplates as Anode Material for Lithium-Ion Batteries
}

\author{
Haipeng Li, ${ }^{1,2,3}$ Yaqiong Wei, ${ }^{1,2,3}$ Yan Zhao, ${ }^{1,2}$ Yongguang Zhang, ${ }^{1,2}$ Fuxing Yin, ${ }^{1,2}$ \\ Chengwei Zhang, ${ }^{1,2}$ and Zhumabay Bakenov ${ }^{4}$ \\ ${ }^{1}$ Research Institute for Energy Equipment Materials, Hebei University of Technology, Tianjin 300130, China \\ ${ }^{2}$ Tianjin Key Laboratory of Laminating Fabrication and Interface Control Technology for Advanced Materials, \\ Hebei University of Technology, Tianjin 300130, China \\ ${ }^{3}$ School of Material Science \& Engineering, Hebei University of Technology, Tianjin 300130, China \\ ${ }^{4}$ Institute of Batteries LLC, Nazarbayev University, Kabanbay Batyr Avenue 53, Astana 010000, Kazakhstan
}

Correspondence should be addressed to Yongguang Zhang; yongguangzhang@hebut.edu.cn and Zhumabay Bakenov; zbakenov@nu.edu.kz

Received 18 September 2015; Revised 14 December 2015; Accepted 20 December 2015

Academic Editor: Philippe Knauth

Copyright (C) 2016 Haipeng Li et al. This is an open access article distributed under the Creative Commons Attribution License, which permits unrestricted use, distribution, and reproduction in any medium, provided the original work is properly cited.

Hexagonal $\mathrm{ZnO}$ nanoplates were synthesized via simple one-pot hydrothermal reaction of $\mathrm{Zn}\left(\mathrm{CH}_{3} \mathrm{COO}\right)_{2}$ and $\mathrm{CO}(\mathrm{NH})_{2}$. XRD, SEM, and HRTEM were used to investigate the composition and microstructure of the material. Together with the facile strain relaxation during structure and volume change upon cycling, this plate-like structure of $\mathrm{ZnO}$ is favorable for physical and chemical interactions with lithium ions because of its large contact area with the electrolyte, providing more active sites and short diffusion distances. The resulting hexagonal $\mathrm{ZnO}$ nanoplates electrode exhibited good cyclability and delivered a reversible discharge capacity of $368 \mathrm{mAh} \mathrm{g}^{-1}$ after 100 cycles at $0.1 \mathrm{C}$.

\section{Introduction}

Lithium-ion batteries (LIBs), the most widely used rechargeable battery for mobile electronic devices, are rapidly expanding their range of applications into fields such as hybrid electrical vehicles (HEV) and electrical vehicles (EV) $[1$, 2]. This strong market demand stimulates the need for development of advanced lithium-ion batteries with larger specific capacities and higher energy densities. Graphite, owning a low theoretical capacity of $372 \mathrm{mAh} \mathrm{g}^{-1}$, represents the state-of-the-art anode material, which greatly limits the further application of the LIBs [3-5]. This is why, among other promising alternatives, $\mathrm{ZnO}$ has been proposed as a more suitable candidate anode for next generation systems based on its much higher theoretical capacity of $978 \mathrm{mAh} \mathrm{g}^{-1}$; in addition, $\mathrm{ZnO}$ has several other advantages, such as low cost, facile preparation, and a high chemical stability [6-8].

Despite these considerable advantages, there are still huge challenges to overcome for $\mathrm{ZnO}$ to promote its application in LIBs. Among these is a low reversible capacity, which is consumed rapidly due to severe volume variations of $\mathrm{ZnO}$ particles during the charge/discharge process [9]. Recently, great efforts have been devoted to improve the electrochemical performance of $\mathrm{ZnO}$ anodes. Numerous $\mathrm{ZnO}$-based microstructural designs, including porous $\mathrm{ZnO}$ [10], $\mathrm{ZnO}$ nanofibers [11], and $\mathrm{ZnO}$ nanoparticles [12], have been proposed to mitigate the electrode failure due to volume changes. Among various nanostructures, one-dimensional (1D) nanostructures have received considerable attention because the $1 \mathrm{D}$ nanostructure is favorable for physical or chemical interactions between the electrodes and lithium ions due to its high surface area and large surface-to-volume ratio, which provides more active sites and short lithium-ion diffusion paths [11].

Herein, we describe a simple one-pot method to synthesize hexagonal $\mathrm{ZnO}$ nanoplates by a simple one-pot hydrothermal reaction method. Physical and electrochemical properties of the resultant $\mathrm{ZnO}$ as an anode material for LIBs are also reported. 


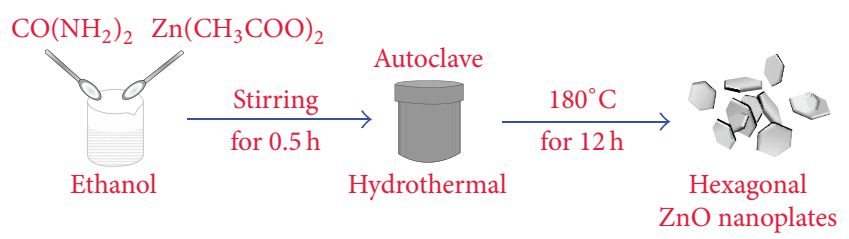

FIGURE 1: Schematics of the preparation of $\mathrm{ZnO}$ nanoplates.

\section{Experimental}

Zinc acetate $\left(\mathrm{Zn}\left(\mathrm{CH}_{3} \mathrm{COO}\right)_{2}, \geq 99 \%\right)$, urea $\left(\mathrm{CO}\left(\mathrm{NH}_{2}\right)_{2}\right.$, $\geq 99 \%)$, and ethanol $\left(\mathrm{CH}_{3} \mathrm{CH}_{2} \mathrm{OH}, \geq 99.7 \%\right)$ were purchased from Tianjin Fuchen Chemical Company and used without further purification. The $\mathrm{ZnO}$ preparation is schematically represented in Figure 1. In a typical experiment, $5 \mathrm{mM}$ of $\mathrm{Zn}\left(\mathrm{CH}_{3} \mathrm{COO}\right)_{2}$ and $10 \mathrm{mM}$ of $\mathrm{CO}\left(\mathrm{NH}_{2}\right)_{2}$ were dissolved in ethanol and stirred for $30 \mathrm{~min}$ using a magnetic stirrer. Subsequently, $60 \mathrm{~mL}$ of mixture was placed in a $100 \mathrm{~mL}$ autoclave at $180^{\circ} \mathrm{C}$ for $12 \mathrm{~h}$ and then cooled to room temperature. The precipitation was alternately centrifuged and washed with distilled water for several times. Finally, the obtained white solid product was dried at $60^{\circ} \mathrm{C}$ for $24 \mathrm{~h}$ in a vacuum oven.

The crystalline phases of the sample were determined by X-ray diffraction (XRD, SmartLab, Rigaku Corporation) equipped with $\mathrm{Cu} \mathrm{K} \alpha$ radiation. The sample morphology was examined by scanning electron microscopy (SEM, S4800, Hitachi Limited). The interior structure of sample was observed using transmission electron microscopy (TEM, JEM-2100F, JEOL) at $160 \mathrm{kV}$.

The electrochemical performance of sample was investigated using coin-type cells (CR2025). The cell was composed of lithium metal (counter and the reference electrodes) and hexagonal $\mathrm{ZnO}$ nanoplate electrode separated by a microporous polypropylene separator soaked in $1 \mathrm{M} \mathrm{LiPF}_{6}$ in a mixture of dimethyl carbonate/diethyl carbonate/ethylene carbonate (1:1:1 by volume) electrolyte. The $\mathrm{ZnO}$ electrode was prepared by mixing $70 \mathrm{wt} \%$ as-prepared hexagonal $\mathrm{ZnO}$ nanoplate powders, $10 \mathrm{wt} \%$ polyvinylidene fluoride (PVDF) (Kynar, HSV900) as a binder, and $20 \mathrm{wt} \%$ acetylene black (MTI, 99.5\% purity) conducting agent in 1-methyl2 -pyrrolidinone (NMP, Sigma-Aldrich, $\geq 99.5 \%$ purity). The resultant slurry was uniformly spread onto nickel foam using a doctor blade and dried at $50^{\circ} \mathrm{C}$ for $12 \mathrm{~h}$. The resulting anode film was used to prepare the electrodes by punching circular disks with $1 \mathrm{~cm}$ in diameter. The active material loading in each electrode was about $2 \mathrm{mg} \mathrm{cm}^{-2}$. The coin cells were assembled in an $\operatorname{Ar}$ (99.9995\%) filled glove box (MBRAUN) and tested galvanostatically on a multichannel battery tester (BTS-5V5mA, Neware) between 0.005 and $3 \mathrm{~V}$ versus $\mathrm{Li}^{+} / \mathrm{Li}$ electrode at different current densities.

\section{Results and Discussion}

$\mathrm{XRD}$ analysis measurements were employed to investigate the hexagonal $\mathrm{ZnO}$ nanoplates; Figure 2 shows typical XRD patterns of the $\mathrm{ZnO}$ sample. XRD pattern is consistent with

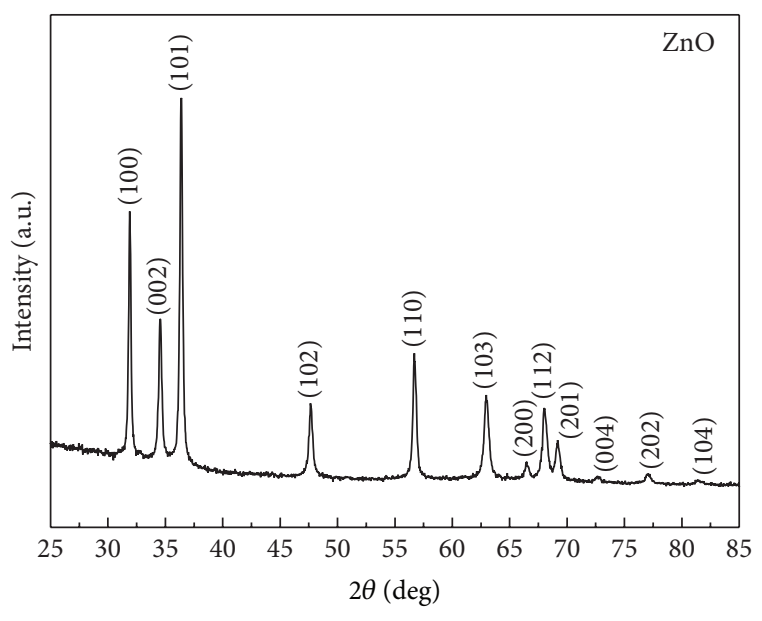

FIGURE 2: XRD patterns of as-prepared $\mathrm{ZnO}$ sample.

the JCPDS Card number 36-1451, confirming that a product with the $\mathrm{ZnO}$ hexagonal structure with space group p63mc and the lattice parameters $a=0.3257 \mathrm{~nm}, c=0.52156 \mathrm{~nm}$ [10] was successfully synthesized. The XRD peaks at $2 \theta=$ $31.8^{\circ}, 34.4^{\circ}, 36.3^{\circ}, 47.6^{\circ}, 56.6^{\circ}, 62.9^{\circ}, 66.4^{\circ}, 67.9^{\circ}, 69.1^{\circ}, 72.6^{\circ}$, $76.9^{\circ}$, and $81.4^{\circ}$ could be assigned to (100), (002), (101), (102), (110), (103), (200), (112), (201), (004), (202), and (104) planes of $\mathrm{ZnO}$ [13].

The $\mathrm{ZnO}$ sample morphology was investigated by SEM (Figure 3(a)). The data confirm as well that hexagonal nanoplates of $\mathrm{ZnO}$ were successfully prepared via a simple one-pot hydrothermal reaction of $\mathrm{Zn}\left(\mathrm{CH}_{3} \mathrm{COO}\right)_{2}$ and $\mathrm{CO}\left(\mathrm{NH}_{2}\right)_{2}$. $\mathrm{ZnO}$ was developed with regular nanoplate shapes with an average diameter of around $800 \mathrm{~nm}$ and a thickness of around $85 \mathrm{~nm}$; it can be seen that the nanoplates are interconnected, and this may lead to a better electric contact among the active particles [10]. As a result, the electrochemical reactions of the active materials can proceed quicker and more efficiently resulting in an enhanced capacity and high rate capability, as it was confirmed in the following electrochemical tests. Figure 3(b) exhibits the TEM images of $\mathrm{ZnO}$ sample showing the formation of hexagonal structured $\mathrm{ZnO}$ with a wide range size distribution. At a higher magnification (Figure 3(c)), HRTEM of ZnO sample shows the crystal lattice strips with a measured neighboring interlayer distance of $2.82 \AA$, which corresponds to the reported value of interplanar spacing $\left(d_{100}\right)$ of $(100)$ lattice plane of hexagonal $\mathrm{ZnO}$ phase (JCPDS Card number 361451) [14]. This suggestion is in a good agreement with the XRD results showing that the as-prepared $\mathrm{ZnO}$ sample is highly crystalline exhibiting strong and sharp reflection peaks, which is further confirmed by HRTEM equipped with the selected area electronic diffraction (SAED). Figure 3(d) shows the corresponding SAED (the single particle in Figure 3(c)) pattern of the sample, indicating that the $\mathrm{ZnO}$ nanoplates show a single crystalline structure [15]. Xiao et al. showed that the degree of crystallinity of nanostructured $\mathrm{ZnO}$ greatly influences the electrochemical performance of $\mathrm{ZnO}$ as anode in lithium-ion batteries, and the specific capacity of $\mathrm{ZnO}$ can be improved by enhancing the degree 


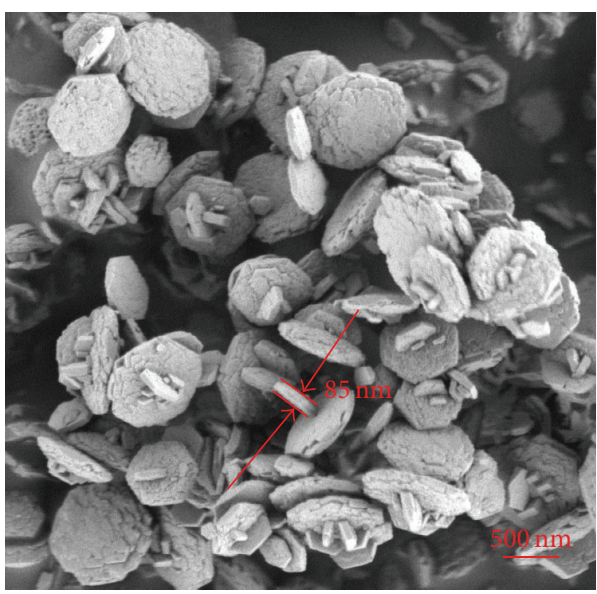

(a)

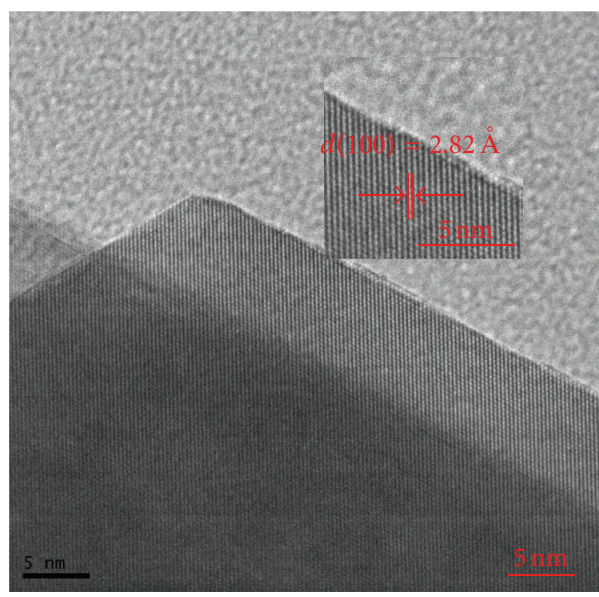

(c)

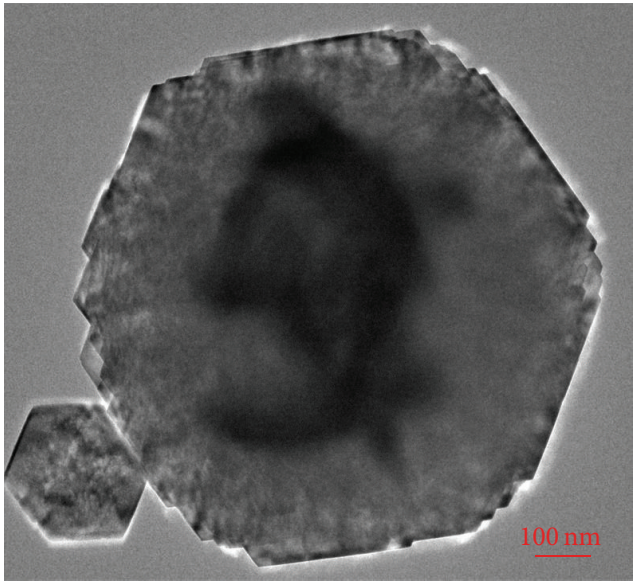

(b)

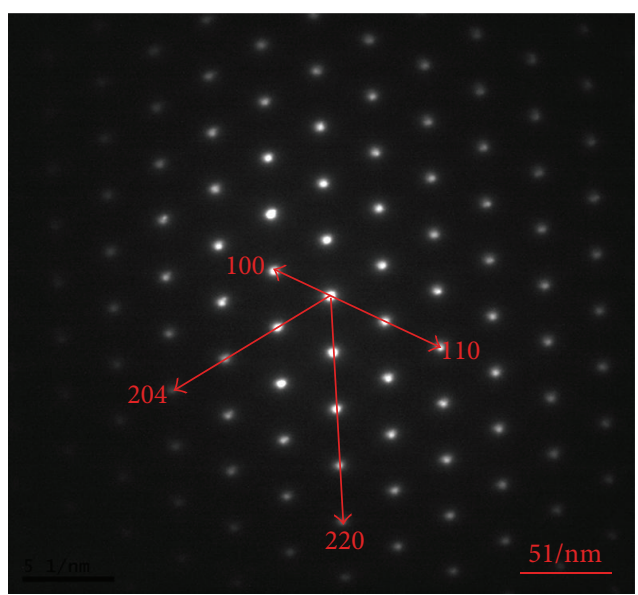

(d)

FIgURE 3: (a) SEM image of ZnO sample; (b) TEM image of ZnO sample; (c) HRTEM images of ZnO sample; (d) SAED pattern of ZnO sample.

of crystallinity, which will facilitate the alloying and dealloying processes of the reduction product of $\mathrm{ZnO}$ [16]. Herein, as-prepared $\mathrm{ZnO}$ particles with high crystallinity could be a good candidate anode for battery applications; the following electrochemical studies have confirmed this suggestion.

Figure 4 illustrates the galvanostatic discharge/charge curves of the electrode containing the hexagonal $\mathrm{ZnO}$ nanoplates during the initial three cycles at $0.1 \mathrm{C}$. A very obvious plateau located at $0.5-0.6 \mathrm{~V}$ versus $\mathrm{Li} / \mathrm{Li}^{+}$appears in the first discharge curve. This plateau corresponds to the reduction process of $\mathrm{ZnO}$ to $\mathrm{Zn}$ metal $(\mathrm{ZnO}+2 \mathrm{Li} \rightarrow \mathrm{Zn}$ $+\mathrm{Li}_{2} \mathrm{O}$ ). Upon deep discharge, the second voltage plateau can be observed at $0.2 \mathrm{~V}$ versus $\mathrm{Li} / \mathrm{Li}^{+}$corresponding to the formation of lithium-zinc alloy $\left(x \mathrm{Li}+\mathrm{Zn} \rightarrow \mathrm{Li}_{x} \mathrm{Zn}\right)$. However, in the second and subsequent discharging processes, the above plateaus are not so obvious. The synthesized $\mathrm{ZnO}$ nanoplate delivers first discharge capacities of $1702 \mathrm{mAh} \mathrm{g}^{-1}$, which is much higher than theoretical value of the material, $978 \mathrm{mAh} \mathrm{g}^{-1}$. Such result suggests extra lithium consumption during the solid electrolyte interface (SEI) layer formation, and the formation of an SEI layer consumes a certain percentage of lithium, which is all quite common for most anode materials $[8,17]$, and these processes lead to a larger polarization between the reduction and oxidation peaks. After the initial activation, the slopes in discharge curves are changed, and the potential profiles in the subsequent cycles are similar in shape, indicating that the lithiation process of $\mathrm{ZnO}$ is reversible [18].

The galvanostatic cycling performance of the $\mathrm{ZnO}$ electrodes at $0.1 \mathrm{C}$ is depicted in Figure 5. The system achieves reversible capacity of $871 \mathrm{mAh} \mathrm{g}^{-1}$ in the second cycle and shows a good cycling stability with a reversible capacity of $368 \mathrm{mAh} \mathrm{g}^{-1}$ after 100 cycles. Furthermore, except for the initial three cycles, the coulombic efficiency of the cell is higher than $90 \%$ during the 100 cycles, which indicates a successful accommodation of the mechanical strain upon cycling by the $\mathrm{ZnO}$ plate-like nanostructure.

To further investigate the electrochemical properties of the $\mathrm{ZnO}$ electrode, the cyclability data at $1.5 \mathrm{C}$ were 


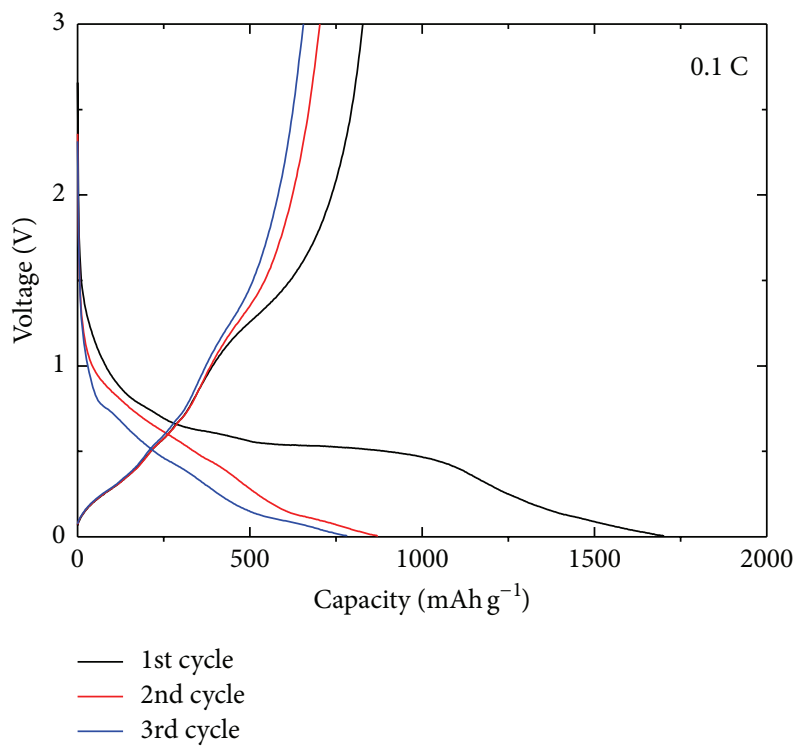

FIGURE 4: Discharge/charge profiles of lithium cell with $\mathrm{ZnO}$ electrode at $0.1 \mathrm{C}$.

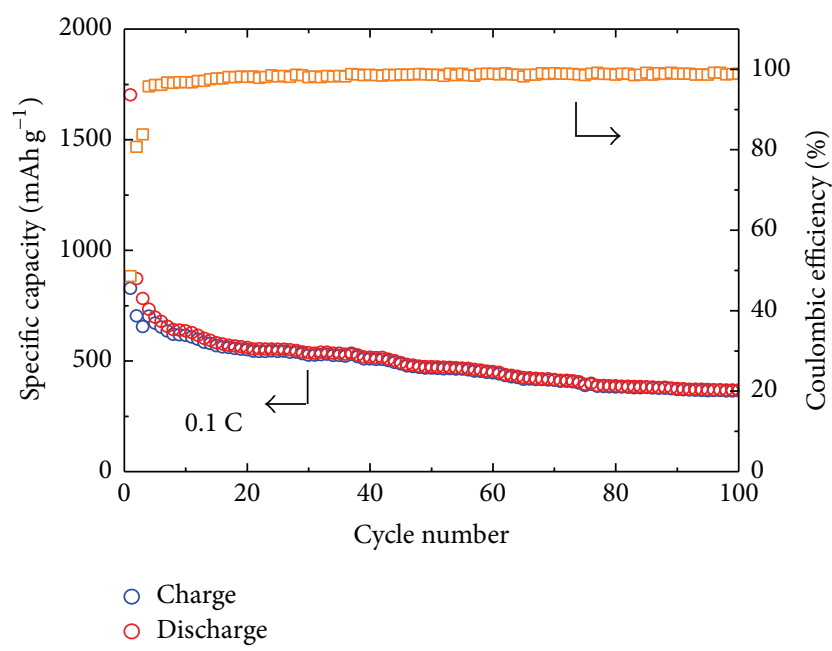

Figure 5: Cycle performance of lithium cell with $\mathrm{ZnO}$ electrode at $0.1 \mathrm{C}$.

conducted as shown in Figure 6. Although the $\mathrm{ZnO}$ electrode shows a limited capability of $208 \mathrm{mAh} \mathrm{g}^{-1}$ at the 2 nd cycle, the cell exhibits stable cyclability with a capacity retention of $67 \%$ over 100 cycles. It could be suggested that nanoplate structure of the $\mathrm{ZnO}$ favors the rate capability, as further confirmed by the following study.

The rate capability results, as depicted in Figure 7, reveal the excellent high current density performance of the $\mathrm{ZnO}$ electrodes. After the initial activation at $0.5 \mathrm{C}$, the electrode delivers a reversible discharge capacity of $610 \mathrm{mAh} \mathrm{g}^{-1}$ at the 2nd cycle. There is a gradual capacity reduction with the current density increase, although a reversible capacity of $207 \mathrm{mAh} \mathrm{g}^{-1}$ was sustained even at 1.5 C. More importantly, when the current rate was relaxed back to a low current

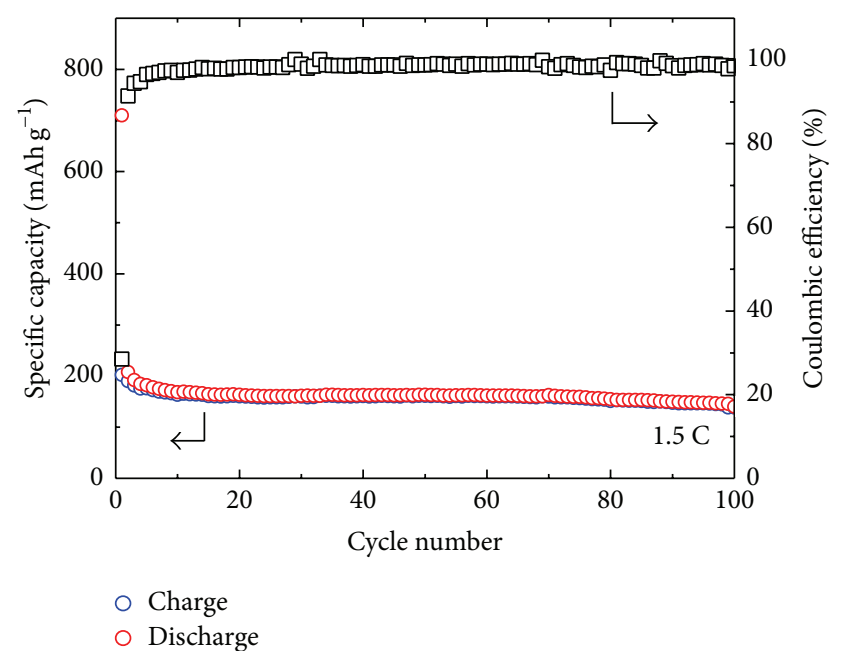

Figure 6: Cycle performance of lithium cell with $\mathrm{ZnO}$ electrode at $1.5 \mathrm{C}$.

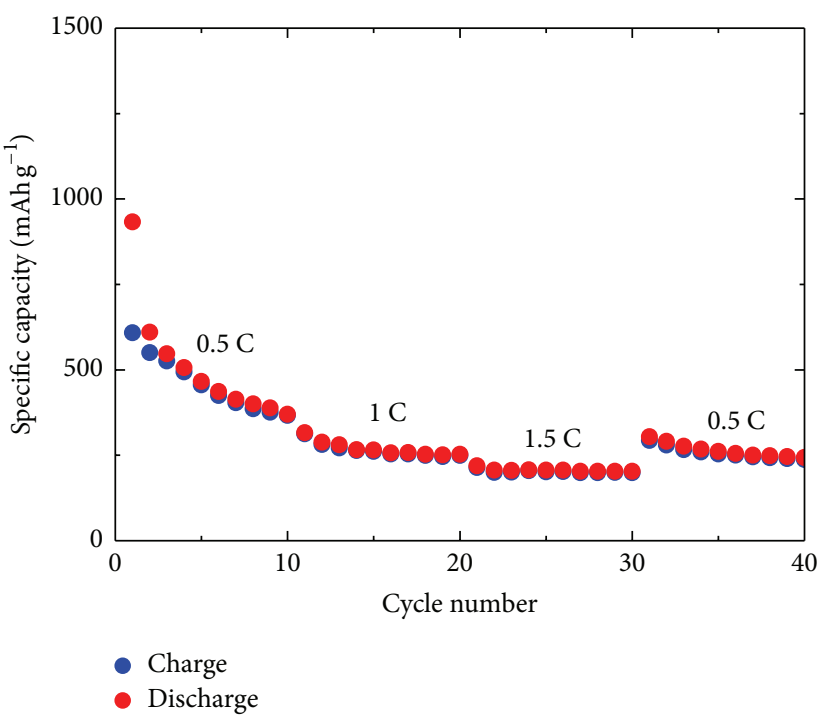

FIgURE 7: Rate capability of lithium cells with the $\mathrm{ZnO}$ electrode.

density of $0.5 \mathrm{C}$, the $\mathrm{ZnO}$ electrode recovered its capacity and continued to deliver a capacity of $304 \mathrm{mAh} \mathrm{g}^{-1}$. This enhanced rate performance could be, again, attributed to the nanoplate structure of the material, which provides a large contact interfaces between electrode and electrolyte and short diffusion paths of lithium ions.

Figure 8 shows the SEM images of fresh and cycled $\mathrm{ZnO}$ electrodes. It can be seen from Figure 8 that the $\mathrm{ZnO}$ electrode morphology changes upon cycling, and the $\mathrm{ZnO}$ nanosheets merge into a large solid bulk, negatively affecting the battery performance. That well matches the fast capacity fading during the initial ten cycles.

The excellent capacity of the $\mathrm{ZnO}$ nanoplate is highly attractive when compared with other reported $\mathrm{ZnO}$-based anode materials (Table 1). It can be observed here that the discharge capacity reaches $368 \mathrm{mAhg}^{-1}$ after 100 cycles. Therefore, the good electrochemical performance of $\mathrm{ZnO}$ 


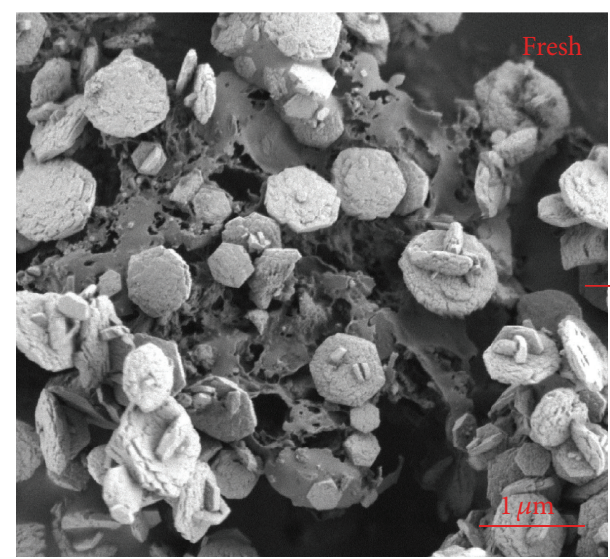

(a)

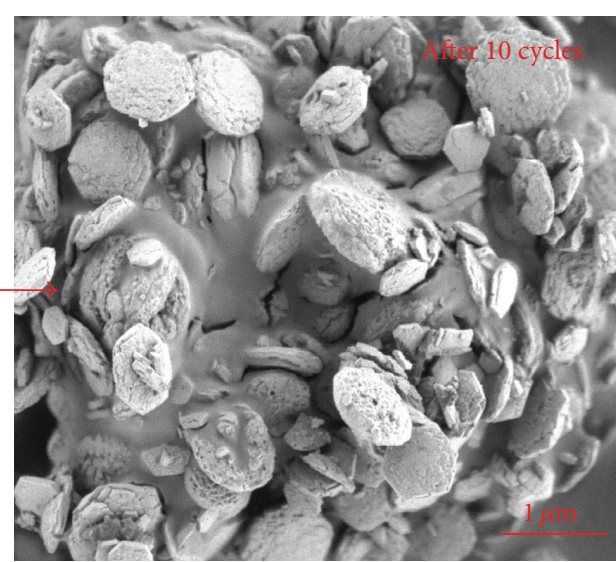

(b)

Figure 8: SEM images of $\mathrm{ZnO}$ electrodes before and after 10 charge/discharge cycles.

TABLE 1: Electrochemical performance comparison of $\mathrm{ZnO}$-based anodes for lithium-ion batteries.

\begin{tabular}{|c|c|c|c|c|c|}
\hline Sample (morphology) & $\begin{array}{c}\text { Reversible } \\
\text { capacity } \\
\left(\mathrm{mAh} \mathrm{g}^{-1}\right)\end{array}$ & Cycle number & Applied potential range $(\mathrm{V})$ & Current density & Reference \\
\hline $\mathrm{ZnO}$ (radial hollow microparticles) & 320 & 100th & $0.005-3.0$ & $0.2 \mathrm{Ag}^{-1}$ & {$[19]$} \\
\hline $\mathrm{ZnO}$ (nanowire) & 252 & 30 th & $0.005-3.0$ & $0.12 \mathrm{Ag}^{-1}$ & {$[20]$} \\
\hline $\mathrm{ZnO}$ (flower-like microaggregates) & 179 & 200th & $0.02-2.8$ & $1 \mathrm{C}$ & {$[21]$} \\
\hline $\mathrm{ZnO}$ (dandelion-like nanorod arrays) & $\sim 310$ & 40th & $0-3.0$ & $0.25 \mathrm{Ag}^{-1}$ & {$[22]$} \\
\hline $\mathrm{ZnO}-\mathrm{C}$ (flower-like nanowall arrays) & 316 & 50 th & $0-3.0$ & $0.5 \mathrm{C}$ & {$[23]$} \\
\hline $\mathrm{ZnO}$ (flower-like arrays) & 238 & 50 th & $0-3.0$ & $0.5 \mathrm{C}$ & [23] \\
\hline $\mathrm{ZnO}$ (microrod) & 150 & 50 th & $0-3.0$ & $0.5 \mathrm{Ag}^{-1}$ & {$[14]$} \\
\hline $\mathrm{ZnO}$ (nanowall arrays) & $\sim 200$ & 40th & $0.02-2.0$ & $0.12 \mathrm{Ag}^{-1}$ & {$[15]$} \\
\hline $\mathrm{ZnO}$ (flower-like microparticles) & $\sim 200$ & 50 th & $0.02-3.0$ & $0.12 \mathrm{Ag}^{-1}$ & {$[24]$} \\
\hline $\mathrm{ZnO}$ nanoplates & 368 & 100th & $0.005-3.0$ & $0.1 \mathrm{C}$ & Our work \\
\hline
\end{tabular}

nanoplate makes it greatly promising for practical application.

\section{Conclusions}

In summary, the hexagonal $\mathrm{ZnO}$ nanoplates were successfully synthesized by a simple one-pot hydrothermal method. Asprepared $\mathrm{ZnO}$ electrode exhibited a high initial discharge capacity of $1702 \mathrm{mAh} \mathrm{g}^{-1}$, and along with a coulombic efficiency close to $100 \%$ it maintained a reversible capacity of $368 \mathrm{mAh} \mathrm{g}^{-1}$ after 100 cycles at $0.1 \mathrm{C}$. Morphological and electrochemical data suggest that the enhanced electrochemical performance stems from the $1 \mathrm{D}$ plate-like structure of $\mathrm{ZnO}$, which provides more active sites, shorter diffusion distances, and better accommodation for large strains upon chargedischarge operation.

\section{Conflict of Interests}

The authors declare that there is no conflict of interests regarding the publication of this paper.

\section{Acknowledgments}

The authors acknowledge the financial support from the National Natural Science Foundation of China (Grant no. 21406052), the Program for the Outstanding Young Talents of Hebei Province (Grant no. BJ2014010), the Natural Science Foundation of Hebei Province of China (Project no. E2015202037), the Science and Technology Correspondent Project of Tianjin (Project no. 14JCTPJC00496), and research Grants from the Ministry of Education and Science of Kazakhstan (3756/GF4 and 4649/GF).

\section{References}

[1] Y. Zhao, Y. Zhang, Z. Bakenov, and P. Chen, "Electrochemical performance of lithium gel polymer battery with nanostructured sulfur/carbon composite cathode," Solid State Ionics, vol. 234, pp. 40-45, 2013.

[2] Y. Zhang, Y. Zhao, K. E. K. Sun, and P. Chen, "Development in lithium/sulfur secondary batteries," The Open Materials Science Journal, vol. 5, pp. 215-221, 2011. 
[3] W.-J. Zhang, "A review of the electrochemical performance of alloy anodes for lithium-ion batteries," Journal of Power Sources, vol. 196, no. 1, pp. 13-24, 2011.

[4] J. B. Goodenough, "Evolution of strategies for modern rechargeable batteries," Accounts of Chemical Research, vol. 46, no. 5, pp. 1053-1061, 2013.

[5] M. M. Thackeray, C. Wolverton, and E. D. Isaacs, "Electrical energy storage for transportation-approaching the limits of, and going beyond, lithium-ion batteries," Energy \& Environmental Science, vol. 5, no. 7, pp. 7854-7863, 2012.

[6] H. Yue, Z. Shi, Q. Wang et al., "MOF-Derived cobalt-doped $\mathrm{ZnO} @ \mathrm{C}$ composites as a high-performance anode material for lithium-ion batteries," ACS Applied Materials \& Interfaces, vol. 6, no. 19, pp. 17067-17074, 2014.

[7] M.-S. Wu and H.-W. Chang, "Self-assembly of NiO-coated $\mathrm{ZnO}$ nanorod electrodes with core-shell nanostructures as anode materials for rechargeable lithium-ion batteries," Journal of Physical Chemistry C, vol. 117, no. 6, pp. 2590-2599, 2013.

[8] M. V. Reddy, G. V. Subba Rao, and B. V. R. Chowdari, "Metal oxides and oxysalts as anode materials for Li ion batteries," Chemical Reviews, vol. 113, no. 7, pp. 5364-5457, 2013.

[9] X. Chen, Y. Huang, X. Zhang, C. Li, J. Chen, and K. Wang, "Graphene supported $\mathrm{ZnO} / \mathrm{CuO}$ flowers composites as anode materials for lithium ion batteries," Materials Letters, vol. 152, pp. 181-184, 2015.

[10] X. H. Huang, X. H. Xia, Y. F. Yuan, and F. Zhou, "Porous ZnO nanosheets grown on copper substrates as anodes for lithium ion batteries," Electrochimica Acta, vol. 56, no. 14, pp. 49604965, 2011.

[11] J. Zhu, G. Zhang, S. Gu, and B. $\mathrm{Lu},{ }^{\mathrm{S}} \mathrm{SnO}_{2}$ nanorods on zno nanofibers: a new class of hierarchical nanostructures enabled by electrospinning as anode material for high-performance lithium-ion batteries," Electrochimica Acta, vol.150, pp. 308-313, 2014.

[12] G. Z. Yang, H. W. Song, H. Cui, Y. C. Liu, and C. X. Wang, "Ultrafast Li-ion battery anode with superlong life and excellent cycling stability from strongly coupled $\mathrm{ZnO}$ nanoparticle/conductive nanocarbon skeleton hybrid materials," Nano Energy, vol. 2, no. 5, pp. 579-585, 2013.

[13] L. Jiang and L. Gao, "Fabrication and characterization of $\mathrm{ZnO}$-coated multi-walled carbon nanotubes with enhanced photocatalytic activity," Materials Chemistry \& Physics, vol. 91, no. 2-3, pp. 313-316, 2005.

[14] X. H. Huang, J. B. Wu, Y. Lin, and R. Q. Guo, “ZnO microrod arrays grown on copper substrates as anode materials for lithium ion batteries," International Journal of Electrochemical Science, vol. 7, no. 8, pp. 6611-6621, 2012.

[15] M. Ahmad, S. Yingying, H. Sun, W. Shen, and J. Zhu, " $\mathrm{SnO}_{2} /$ $\mathrm{ZnO}$ composite structure for the lithium-ion battery electrode," Journal of Solid State Chemistry, vol. 196, pp. 326-331, 2012.

[16] L. Xiao, D. Mei, M. Cao, D. Qu, and B. Deng, "Effects of structural patterns and degree of crystallinity on the performance of nanostructured $\mathrm{ZnO}$ as anode material for lithium-ion batteries," Journal of Alloys and Compounds, vol. 627, pp. 455462, 2015.

[17] P. Poizot, S. Laruelle, S. Grugeon, L. Dupont, and J.-M. Tarascon, "Nano-sized transition-metal oxides as negative-electrode materials for lithium-ion batteries," Nature, vol. 407, no. 6803, pp. 496-499, 2000.

[18] J. Yan, G. Wang, H. Wang et al., "Preparation and electrochemical performance of bramble-like $\mathrm{ZnO}$ array as anode materials for lithium-ion batteries," Journal of Nanoparticle Research, vol. 17, no. 1, pp. 1-10, 2015.

[19] G. Yuan, G. Wang, H. Wang, and J. Bai, "Synthesis and electrochemical investigation of radial $\mathrm{ZnO}$ microparticles as anode materials for lithium-ion batteries," Ionics, vol. 21, no. 2, pp. 365-371, 2014.

[20] J. Wang, N. Du, H. Zhang, J. Yu, and D. Yang, "Layer-by-layer assembly synthesis of $\mathrm{ZnO} / \mathrm{SnO}_{2}$ composite nanowire arrays as high-performance anode for lithium-ion batteries," Materials Research Bulletin, vol. 46, no. 12, pp. 2378-2384, 2011.

[21] V. Cauda, D. Pugliese, N. Garino et al., "Multi-functional energy conversion and storage electrodes using flower-like Zinc oxide nanostructures," Energy, vol. 65, pp. 639-646, 2014.

[22] H. Wang, Q. Pan, Y. Cheng, J. Zhao, and G. Yin, "Evaluation of $\mathrm{ZnO}$ nanorod arrays with dandelion-like morphology as negative electrodes for lithium-ion batteries," Electrochimica Acta, vol. 54, no. 10, pp. 2851-2855, 2009.

[23] Z. Wu, L. Qin, and Q. Pan, "Fabrication and electrochemical behavior of flower-like $\mathrm{ZnO}-\mathrm{CoO}-\mathrm{C}$ nanowall arrays as anodes for lithium-ion batteries," Journal of Alloys and Compounds, vol. 509, no. 37, pp. 9207-9213, 2011.

[24] M. Ahmad, S. Yingying, A. Nisar et al., "Synthesis of hierarchical flower-like $\mathrm{ZnO}$ nanostructures and their functionalization by $\mathrm{Au}$ nanoparticles for improved photocatalytic and high performance Li-ion battery anodes," Journal of Materials Chemistry, vol. 21, no. 21, pp. 7723-7729, 2011. 

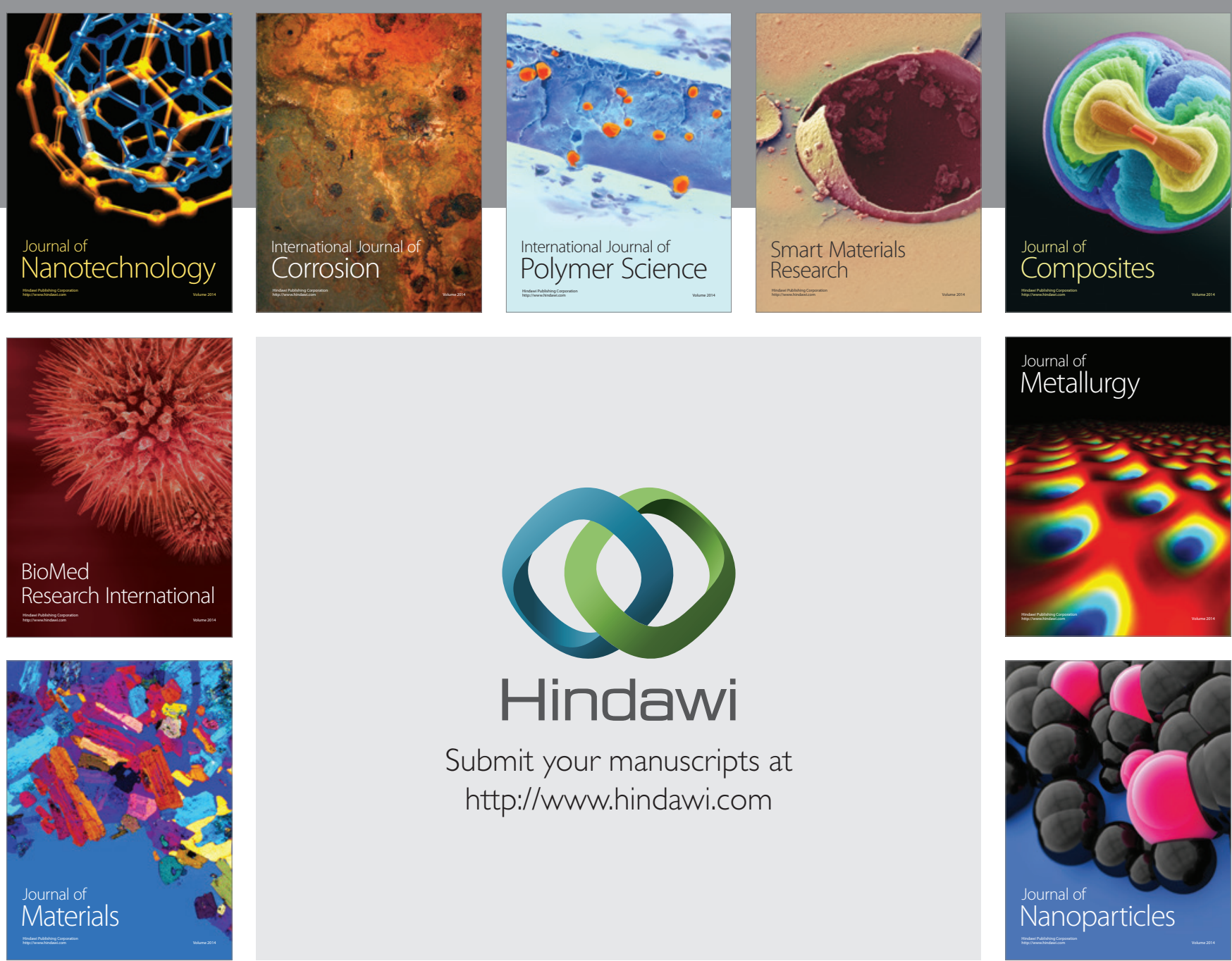

\section{Hindawi}

Submit your manuscripts at

http://www.hindawi.com

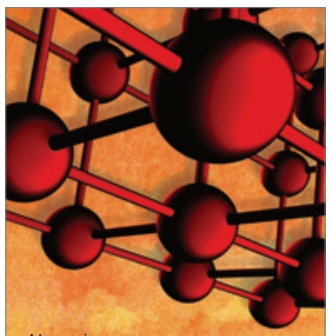

Materials Science and Engineering
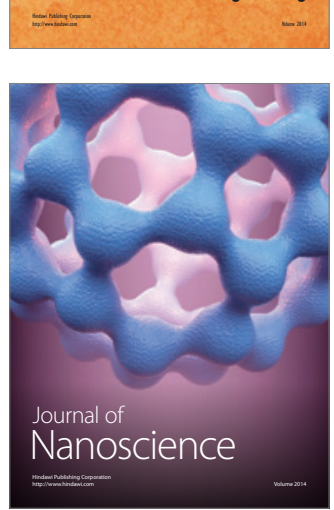
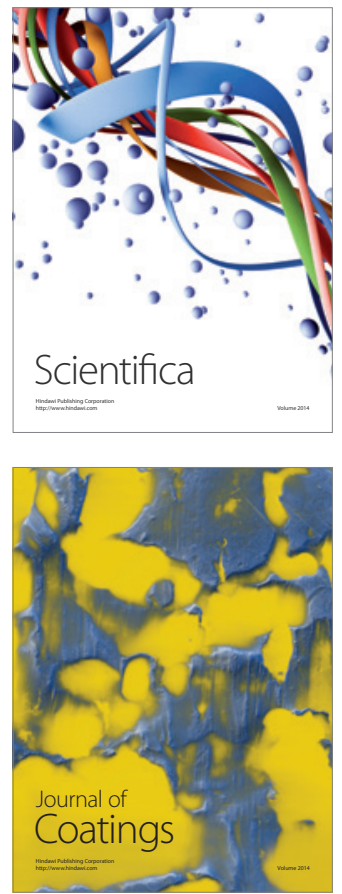
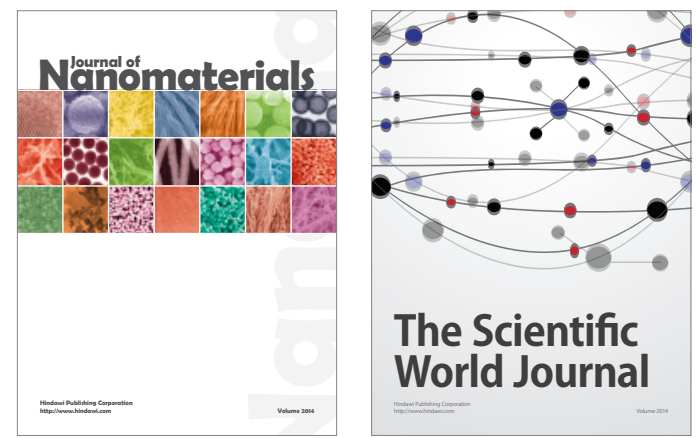

The Scientific World Journal
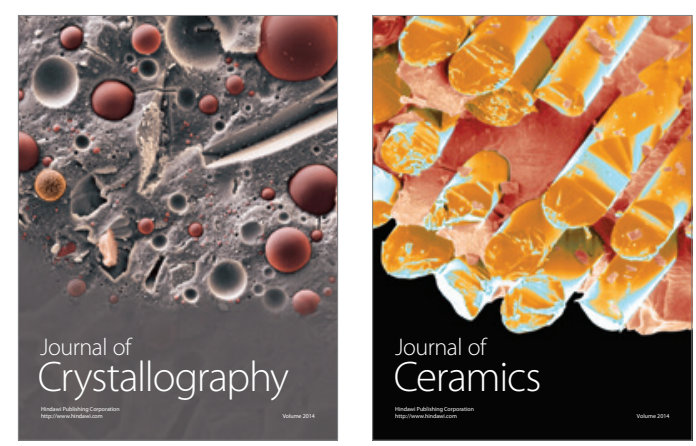
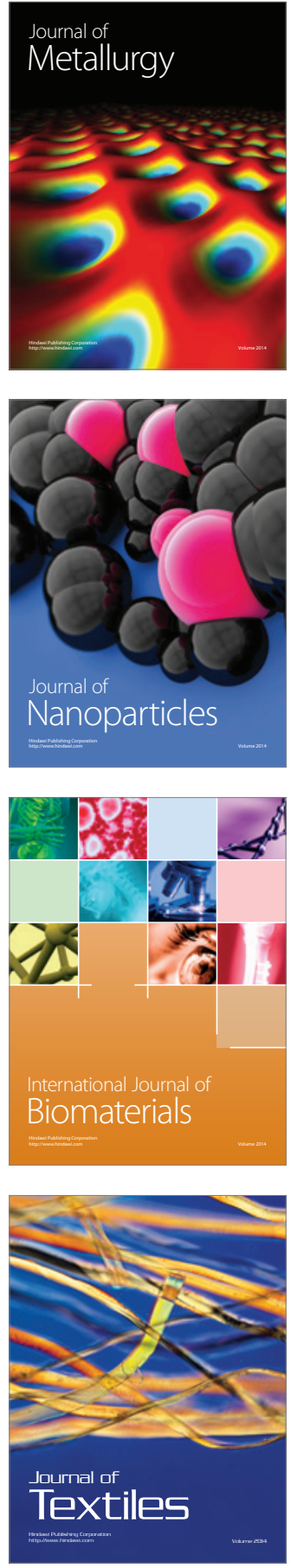